\title{
ANALISIS TINGKAT KEPUASAN KERJA KARYAWAN DALAM MENGELOLA WEDDING EVENT DI THE ROYAL SANTRIAN, TANJUNG BENOA-BALI
}

\author{
Alda Chairani \\ Yayu Indrawati \\ I GPB Sasrawan Mananda \\ Email : chairani.alda@gmail.com \\ PS. S1 Industri Perjalanan Wisata \\ Fakultas Pariwisata UNUD
}

\begin{abstract}
This research aims to determine the employee satisfaction in wedding events at The Royal Santrian and results can be used to improve and optimizing their productivity. The qualitative and quantitative analysis technique are used in this research, and the result will be explained using quantitative description with likert scale approach.

The employee satisfaction is divided into five indicators, such as compensation, promotion, physical environment, non-physical environment, and job characteristic, every indicator include two questions and the total is ten questions. The total score is 103.226 which means that the employees are satisfied while working for wedding event at The Royal Santrian.
\end{abstract}

Keywords: Employee Satisfaction, Wedding Event.

\section{PENDAHULUAN}

Jumlah populasi manusia di dunia yang selalu meningkat setiap tahunnya mengakibatkan kebutuhan yang diperlukan meningkat. Salah satu kebutuhan manusia adalah melakakukan kegiatan perjalanan. Istilah ini dikenal dengan perjalanan wisata, dan orang yang melakukan kegiata wisata disebut wisatawan. Beberapa alasan pullfactor wisatawan melakukan kegiatan wisata antara lain, karena melihat sebuah iklan mengenai destinasi wisata yang berada di suatu daerah. Sedangkan push factor, yaitu untuk kegiatan relaksasi, mengunjungi keluara dan kerabat, menghadiri atau mengadakan suatu event.

Menurut sumber dari pihak The Royal Santrian, salah satu alasan wisatawan mengunjungi Pulau Bali adalah untuk mengadakan dan menghadiri wedding event yang mereka yakini bahwa pernikahan merupakan hal yang sakral sehingga mereka menginginkan pesta yang indah dan tidak terlupakan sepanjang hidup. Dengan kemajuan zaman, wedding event dapat terealisasikan dengan teknologi yang canggih dan kemampuan sumber daya manusia dalam mengoperasikannya. Pada era globalisasi ini, persaingan sangat ketat dilakukan oleh perusahaan, organisasi, maupun lembaga sehingga dituntut untuk senantiasa merancang strategi dan mengimplementasikannya agar dapat bersaing dalam dunia industri.

Persaingan wedding event semakin terasa karena maraknya wedding organizer yang menawarkan jasa dalam menangani sebuah event. Oleh sebab itu, pihak manajemen pada setiap perusahaan dituntut untuk meningkatkan kualitas pelayanan yang diberikan oleh karyawan. Salah satunya, The Royal Santrian yang merupakan salah satu industri pariwisata, yang khususnya bergerak di bidang akomodasi 
dan menyediakan fasilitas wedding event. Pada tahun 2012 The Royal Santrian memenangkan penghargaan dalam kategori "Certificate of Excellence"dari TripAdvisor.

\section{TINJAUAN PUSTAKA}

Menurut As'ad (2001) dasar asumsi dari self report adalah hanya orangnya sendirilah yang paling tahu persis bagaimana perasannya terhadap pekerjaan. Salah satu diantara modelmodel yang sudah biasa digunakan secara luas adalah Minnesota Satisfaction Questionaire $(M S Q)$. Bentuk MSQ dapat berbentuk panjang dengan 100 butir dan berbentuk pendek dengan 20 butir, yaiitu:

1. Dapat bekerja terus sepanjang waktu.

2. Kesempatan mengerjakan pekerjaan sendiri.

3. Kesempatan mengerjakan pekerjaan yang berlaianan dari waktu ke waktu.

4. Kesempatan bekerja kelompok.

5. Cara pemimpin menghadapi pekerjannya.

6. Kecakapan pengawas dalam membuat keputusan.

7. Dapat mengerjakan sesuatu sesuai dengan pendapat.

8. Cara pekerjaan memberikan kepastian kerja.

9. Kesempatan menceritakan pekerjaan kepada orang lain.

10. Kesempatan membantu teman, kalau mereka mendapat kesulitan.

11. Kesempatan mengerjakan sesuatu yang menggunakan kemampuan.

12. Cara kebijakan perluasan diterapkan.

13. Upah serta jumlah pekerjaan yang dikerjakan.

14. Kesempatan promosi dalam pekerjaan.

15. Kebebasan menggunakan hasil keputusan sendiri.

16. Kesempatan mengunakan metode sendiri dalam mengerjakan pekerjaan sendiri.

17. Kondisi kerja

18. Cara teman bekerja sama.

19. Hadiah yang diterima bila pekerjaan dapat dikerjakan dengan baik.

20. Perasaan berprestasi yang diperoleh dari pekerjaan.

\section{METODE PENELITIAN}

Penelitian dilakukan di The Royal Santrian yang berlokasi padaJalan Pratama, Tanjung Benoa-Bali80361. Definisi operasinal variabel yang digunakan, yaitu kompensasi, promosi, lingkungan fisik, lingkungan non fisik, dan karakteristik pekerjaan. Pengumpulan data dilakukan dengan cara wawancara, kuisinoner, dan studi kepustakan. Analisis data yang digunakan dengan menggunakan skala likert yang bersumber dari 14 karyawan. Teknik penentuan sampel ditentukan dengan metode judgemental sampling.

\section{HASIL DAN PEMBAHASAN}

Salah satu fasilitas yang dikelola oleh pihak manajemen adalah wedding event. Sejak keberadaan fasilitias ini sejak 3 tahun silam, total penyelenggaran wedding event sebanyak 150 kali dengan rincian wedding dinner reception, group dinner dan corporate event. Total karyawan tetap yang bekerja untuk menangani wedding event sebanyak 14 orang. Karyawan tersebut diantaranya bekerja sebagai wedding and event coordinator, waiter, waitress, bartender, supervisor floor and bar, assistant food and beverage manager dan hostest. Beberapa persyaratan bekerja sebagai wedding coordinator adalah lulusan D3 bidang perhotelan atau hospitality, menguasi bahasa inggris dengan baik, berwawasan luas, dan mempuyai keinginan untuk selalu belajar.

Harga paket wedding event yang sudah ditetapkan oleh manajemen sebesar Rp.21.000.000++ dan Rp.29.000.000, harga tersebut dikhususkan untuk penyelenggaraan wedding event, sedangkan harga paket dinner reception seharga Rp.38.000.000++ hinga Rp.140.000.000++. Proses pembayaran yang dilakukan oleh konsumen, dilakukan melalui 3 tahap. Pertama, konsumen menetapkan waktu penyelenggaran wedding event dengan membayar uang muka sebesar Rp.10.000.000, kemudian melunaskan $50 \%$ biaya tertanggung dan 14 hari sebelum penyelenggaraan wedding event, diharuskan untuk melunaskan pembayaran. 
4.2 Analisis Kepuasan Kerja Karyawan dalam Mengelola Wedding Event di The Royal Santrian

\author{
Variable dan Indikator \\ Kepuasan Kerja
}

Bobot Tingkat

Kepuasan (\%)
Bobot Tingkat

Kepentingan (\%)

\begin{tabular}{lcc}
\hline A. Kompensasi & & 60 \\
1. Hadiah yang di berikan & 58 & 65 \\
2. Gaji & 61 & 49 \\
\hline B. Promosi & 33 & 67 \\
$\quad$ 3. Upaya dalam kenaikan jabatan & 6 & 65 \\
\hline $\begin{array}{l}\text { C. Lingkungan Fisik } \\
\text { 4. Kelengkapan peralatan dan perlengkapan kerja } \\
\text { 5. Kemudahan penggunaanya }\end{array}$ & 69 & 61 \\
\hline $\begin{array}{l}\text { D. Lingkungan Non Fisik } \\
\text { 6. Kesempatan bekerja dalam kelompok }\end{array}$ & 59 & 61 \\
$\quad \begin{array}{l}\text { 7. Kualitas huungan dengan atasan } \\
\text { 8. Keharmonisan kerja karyawan }\end{array}$ & 55 \\
\hline $\begin{array}{l}\text { E. Karakteristik Pekerjaan } \\
\text { 9. Penerapan kebijakan yang berlaku } \\
\quad \text { 10. Inisiatif karyawan dalam menangani sebuah } \\
\quad \text { complaint }\end{array}$ & 57 & 56 \\
\hline
\end{tabular}

Berdasarkan tabel tersebut, diketahui bahwa tingkat kepuasan dan tingkat kepentingakan masing-masing indikator berbeda. Hal ini disebabkan oleh kebutuhan masing-masing karyawan.

Variable dan Indikator

Kepuasan Kerja

Tingkat Kesesuaian (\%)

\section{A. Kompensasi}

$\begin{array}{lr}\text { 1. Hadiah yang di berikan } & 96.66\end{array}$

2. Gaji

106.55

\section{B. Promosi}

3. Upaya dalam kenaikan jabatan

148.48

C. Lingkungan Fisik

4. Kelengkapan peralatan dan perlengkapan kerja

97.10

5. Kemudahan penggunaanya

94.20

\section{Lingkungan Non Fisik}

6. Kesempatan bekerja dalam kelompok 103.38

$\begin{array}{ll}\text { 7. Kualitas huungan dengan atasan } & 110.90\end{array}$

8. Keharmonisan kerja karyawan 101.75

\section{E. Karakteristik Pekerjaan}

9. Penerapan kebijakan yang berlaku

86.15

10. Inisiatif karyawan dalam menangani sebuah complaint

87.09

Total

103.226 
Berdasarkan tabel tersebut, total kepuasan karyawan adalah $103.226 \%$, yang artinya adalah karyawan merasakan puas. Puas atau tidak puas ditentukan dari hasil presentase diatas $100 \%$. Persentase terbesar berada pada indikator upaya kenaikan jabatan yang diberikan pihak top management dalam terhadap karyawan yang memiliki performa baik dalam menangani wedding event di The Royal Santrian, yaitu sebesar $148.48 \%$ sedangkan persentase terkecil berada pada indikator penerapan kebijakan yang berlaku dengan total persentase sebesar $86.15 \%$. Berdasarkan data yang didapat, diketahui bahwa karyawan belum merasakan adanya penetapan pasti mengenai job description pada masingmasing jabatan.

\section{SIMPULAN DAN SARAN Simpulan}

The Royal Santrian adalah salah satu akomodasi yang teletak di Tanjung Benoa, Bali dan memiliki 20 kamar berjenis villa dengan kisaran harga Rp.6.000.000,00Rp.10.000.000,00 untuk satu malam malam. Salah satu fasilitas yang paling diminati oleh konsumen adalahwedding event yang dikelola sejak 3 tahun silam oleh pihak manajemen. Pengelolaan wedding event di The Royal Santrian dibawahi oleh departemen Food and Beverage (F\&B) tetapi, pihak manajemen sudah memberikan tanggung jawab penuh kepada event coordinator dalam menanangani eventevent yang akan diselenggarakan. Total karyawan yang mengelola dan menangani wedding event berjumlah 14 orang, dengan rincian 7 orang pelayan, 3 orang bartender, 1 orang wedding coordinator, 1 orang assisten manajer, 1 orang supervisor floor and bar, dan 1 orang hostest.

Berdasarkan pembahasan mengenai tingkat kepuasan kerja karyawan dalam mengelola wedding event di The Royal Santrian, Tanjung Benoa-Bali dari total 14 responden makan dapat ditarik kesimpulan bahwa, karyawan yang bekerja merasakan sangat puas, karena tingkat kesesuaian diatas $100 \%$. Hal ini dapat dilihat dari hasil penelitian dengan rata-rata tingkat kesesuaian sebesar $103.226 \%$.

\section{Saran}

Dalam peningkatan kinerja dan kepuasan kerja karyawan dalam mengelola wedding event di The Royal Santrian, hendaknya selalu memberikan perhatian kepada karyawankaryawannya. Selain itu, diharapakan pihak manajemen melengkapi perlengkapan dan peralatan yang dibutuhkan karyawan guna memudahkan proses kerja selama diadakannya wedding event. Inovasi dan kreatifitas perlu ditingkatakan dalam upaya memuaskan konsumen, dan dengan dibangunnya chapel di The Royal Santrian, diharapkan dapat menarik minat yang lebih banyak dalam menangani wedding event di setiap tahunnya dan disarankan untuk membuat dapartemen tersendiri dalam pengelolaan kegiatan events.

Dalam penerapan kebijakan oleh manajemen, hendaknya lebih diperjelas mengenai job descriprion masing-masing karyawan agar dalam pelaksaan pembagian pekerjaan dapat berjalanan dengan kesesuaian yang berlaku dan dipermudahkannya karyawan untuk melakukan inisiatif dalam menangani sebuh complaint oleh konsumen Selain itu, perlu diadakannya pelatihan spesialisasi dalam penggunaan barang-barang baru yang memiliki tinggat kesukaran yang tinggi dan untuk meningatkan kualitas pelayanan, serta memberikan kelengkapan kerja dan perlengkapan kerja untuk karyawan agar dapat memudahkan proses bekerja.

\section{DAFTAR PUSTAKA}

As'ad, M., 2001.Psikologi Industri, Edisi Keempat, Cetakan Keenam. Yogyakarta: Liberty.

Hasibuan, Malayu. 2001. Manajemen Sumber Daya Manusia. Jakarta : Bumi Aksara.

Luthans, F. 2006. Organizational Behaviour, Eight Edition. Tokyo : Mc. Graw-Hill International book Company.

Noor, Any. 2009. Manajemen Event. Bandung : Alfabeta Bandung. 